\title{
Study on the immunogencity of poly(D,L-lactide-co- glycolide) (PLGA) microspheres-encapsulated vaccine preparation against Stenotrophomonas maltophilia infection in channel catfish (Ictalurus punctatus)
}

\author{
Kai-yu Wang ${ }^{12^{\star}}$, Long-jun Deng ${ }^{1}$, Jin-lu Huang ${ }^{1}, \mathrm{Xi} \mathrm{Fu}^{1}$, De-fang Chen ${ }^{1}$, Yi Geng ${ }^{1}$ and Xiao-li \\ Huang $^{1}$
}

\footnotetext{
${ }^{1}$ Key Laboratory of Animal Disease and Human Health of Sichuan Province, Sichuan Agricultural University, Ya'an, Sichuan 625014, P. R. China.

${ }^{2}$ College of Veterinary Medicine of Sichuan Agricultural University, Yaan, Sichuan, Sichuan 625014, P.R. China.
}

\section{Accepted 7 December, 2010}

The purpose of the experiment is to study the poly(D,L-lactide-co-glycolide) (PLGA) microspheres of coated in fish vaccine formulations. In this study, we prepared Pseudomonas bacteria widowed raise PLGA microspheres vaccine by double emulsion evaporation maltophilia. It was prepared to support the completion of the Stenotrophomonas maltophilia oligonucleotide PLGA microspheres vaccine through injection as well as oral and immersion in three ways inoculated based on body weight (100 \pm 5 g) of channel catfish, each has five immunization groups, of which three group were different doses of the immune group, the other two groups were not coated with $S$. maltophilia raising vaccination with inactivated Aeromonas group and the control group. During the 0, 28 and 56th day, the immunization group were processed in same way. Collection of blood and measuring of immune-related indicators at $0,7 \mathrm{th}, 21 \mathrm{st}, 35^{\text {th }}$ and $49^{\text {th }}$ day were carried out. At the 63th day, $0.2 \mathrm{ml}$ of each fish at the concentration of $1 \times 10^{9} \mathrm{cfu} / \mathrm{ml}$ of Stenotrophomonas widow raising a single cell suspension of viable bacteria was injected into the Channel catfish. Continuous observation and recording of the results of each group shows that the experimental vaccine preparation of PLGA microspheres encapsulation efficiency was $88.93 \%$, the immunization route vaccine group versus those in saline control group significantly enhance the phagocytic activity of white blood cells, serum lysozyme, complement C3, serum protein content and antibody IgM levels. Channel catfish immunized by injection were challenged with live $S$. maltophilia, the relative survival rates of group 3 was $9.16 \%$ higher than group 5; however group 1 was $15 \%$ lower than group 5 ,group 2 was 1.67\%. Another five groups immunized by oral vaccination were challenged with S. maltophilia, the relative survival rates of group 1 to group 3 were $43.33,65$ and $75 \%$, but group 5 was only $6.68 \%$. Conclusively, injection and oral vaccination of Stenotrophomonas widow raising Aeromonas vaccine PLGA microspheres in Channel catfish has a good immune protective effect, while the immersion of the protective effect of various immunization groups was not obvious.

Key words: Stenotrophomonas maltophilia, poly(D,L-lactide-co-glycolide), Ictalurus punctatus, vaccine.

\section{INTRODUCTION}

In recent years, an acute epidemic and infectious disease of Ictalurus punctatus has emerged in many areas in China China, showing signs of enteritis, intussusception and

*Corresponding author. E-mail:kywangsicau@126.com. Tel: 860835-2885753. Fax: 860835-2885302. and archocele (Wang et al., 2006). The sudden infection and high mortality rate due to this disease gravely threatened the healthy development of aquacultive industries of I. punctatus (Geng et al., 2006). There have been some reports on similar cases of such disease in American since 1988. Durborow and Hanson (1988) isolated bacteria such as Aeromonas hydrophila, Pseudomonas spp., Aeromonas sobria and Flavobacterium 
columnaris among others from the organs of sick fish. They discovered that due to certain reasons, there was decrease in blood flow of the intestine leading to the damage of mucosa and subsequently causing such phenomenon like intestinal autolysis with protein enzymes taking place and intestine rupcture, as well as irregular contraction and fold. There has been no evidence to support the inference about the connection between these isolated bacteria and the disease. Wang et al., (2006b) and Geng and Wang (2005) isolated the same high pathogenic Stenotrophomonas maltophilia from different areas whereby the $I$. punctatus had been infected with intus-susception. Artificial recurrent infection experiments show similar clinical symptoms and pathological features compared to natural infection, so the S. maltophilia was proved to be the pathogen of $I$. punctatus' intus-susception.

S. maltophilia is gram-negative bacterium, which belongs to unfermentation type, aerobic and not forming spores. It covers extensively various water sources, soil and plant roots system and is an important source of human and infectious bacteria in hospital. This bacterium can cause sepsis, infective endocarditis, pneumonia, conjunctivitis, encephalitis, urinary tract, gastrointestinal tract infection and wound infection, etc. S. maltophilia could be infectious not only to human but also to terrestrial animal like goats (Johnson, 2003) and pigs (Zhang and Xie, 2004) and also to some aquatic animals. Ben (2002) reported that $S$. maltophilia was a type of critical pathogens of tunain Europe and USA. Meanwhile, this pathogens could also infect aquatic animal like crocodile (Harris, 2001), Cuora flavomarginata (Huang and Chen, 2002), Trachinotus ovatus (Zhou and Zhu, 2001) and Eriocheir sinensis (Li and Jiang 2004). S. maltophilia showed multiple resistance (Hugh, 1961; Qian et al. 2003) to antibiotics owing to its secretion of $\beta$ lactamase and aminoglycoside modifying enzymes. This brought tremendous problems to drug treatment of $I$. punctatus's intussusception resulting from $S$. maltophilia. For example, the residue of antibiotics has led to the prohibition of export of $I$. punctatus from China to Alabama (U.S state) (Liu et al., 1999). So, it was urgent and necessary to adopt vaccination technology to prevent such infection. We chose bacillary antigen of $S$. maltophilia from Ictalurus punctatus to prepare its relevant poly(D,L-lactide-co-glycolide) (PLGA) microsphereencapsulated-encapsulated vaccine. At the same time, we conducted research such as vaccine immunity dosage, immune routes and immunity protective effect on healthy $I$. punctatus to develop a new vaccine for aquacultive industries which could effectively prevent $I$. punctatus from S. maltophilia.

\section{MATERIALS AND METHODS}

\section{Materials}

S. maltophilia came from the identification and conservation of our own laboratory. Healthy I. punctatus, average weight $100 \pm 5 \mathrm{~g}$, were obtained from the Meishan I. punctatus Farm.

\section{The preparation of antigens}

S. maltophilia was inoculated to tryptone soy broth (TSB) under aseptic condition, cultured under shaking at $28^{\circ} \mathrm{C}, 120 \mathrm{r} / \mathrm{min}$ for 24 $\mathrm{h}$. Then, the suspension of cultured bacteria was inactivated by $0.3 \%$ formaldehyde; staved by ultrasonics (300W $10 \mathrm{~min}$ ), and conserved under chill storage at $4^{\circ} \mathrm{C}$.

\section{The preparation of $S$. maltophilia PLGA microsphere- encapsulated vaccine}

Production of S. maltophilia PLGA microsphere-encapsulated vaccine

Biodegradable polymer, PLGA, prepared using the vaccine as a carrier to make $S$. maltophilia, inactivated bacteria vaccine into microspheres vaccine. Using copolymer materials, PLGA (50:50), and adopting the water in oil, oil in water $(\mathrm{W} / \mathrm{O} / \mathrm{W})$ solvent evaporation approaches, was used to produce microspheres within 10 $\mu \mathrm{m}$.; at the package rate, the higher the better (Kim et al., 1999, Jeffery and O'Hagan, 1993). PLGA was dissolved into dichloromethane (bought from Chongqing Chemical Factory) to compound solution of $6 \%$, adding antigenic solution and emulsifying for 3 to 5 min by $6500 \mathrm{r} / \mathrm{min}$ with high speed homogenizer. In the next step, the mixed solution was added into the concentration of $10 \%$, bulk of $30 \mathrm{ml}$ of the polyving alcohol (PVA bought from SIGMA) solution and churn by $1100 \mathrm{r} / \mathrm{min}$, evaporating under ordinary temperature for 12 to $18 \mathrm{~h}$ and centrifuging to collect the microsphere vaccine, then washing with deionized water for three times and freeze-drying it with freeze drier and conserving it at $-20^{\circ} \mathrm{C}$ for backup.

The measurement of technical index of S. maltophilia PLGA microsphere-encapsulated vaccine

\section{Electric mirror observation and particle diameter measurement}

Under solution situation, PLGA microsphere was transferred onto the slide glass and put under microscope (NIKON) to observe the outlook of particles. This allows easy measurement and observation of the diameter of the dried PLGA microspheres.

\section{Encapsulation efficiency measurement}

$20 \mathrm{mg}$ PLGA microsphere vaccine was dissolved with $0.5 \mathrm{ml}, 0.1$ $\mathrm{mol} / \mathrm{l} \mathrm{NaOH}$ and $5 \%$ SDS solution. It was vibrated at $37^{\circ} \mathrm{C}$ for $24 \mathrm{~h}$, centrifuged at $12000 \mathrm{r} / \mathrm{min}$ and the supernatant collected. BCA protein content test kit was used to measure the amount of antigen in liquid supernatant ( $W$ ⿹ $)$ and the amount of antigen that was added when producing microspheres. The encapsulation efficiency was counted using the formula below

$Q_{w \%}=W_{E} / W_{T} \times 100 \%$

\section{Immune experiment}

The immune experiment could be divided into three immune routes, with 5 groups each. Group I, II and III were S. maltophilia PLGA microsphere-encapsulated vaccine with different immune dose. Group IV was physiological saline solution control group, Group V 
Table 1. Changes of phagocytic activity of leucocytes of Ictalurus punctatus in each group.

\begin{tabular}{lccccc}
\hline \multicolumn{1}{c}{ Group } & \multicolumn{5}{c}{ Phagocytic activity of leucocytes of different days } \\
\hline \multicolumn{1}{c}{$\mathbf{0}$ day } & $\mathbf{7}$ days & 21 days & 35 days & 49 days \\
\hline Injection immunity & & & & & \\
Group I & $0.248 \pm 0.007$ & $0.308 \pm 0.010^{\mathrm{A}}$ & $0.364 \pm 0.031^{\mathrm{A}}$ & $0.400 \pm 0.006^{\mathrm{A}}$ & $0.382 \pm 0.005^{\mathrm{A}}$ \\
Group II & $0.254 \pm 0.025$ & $0.337 \pm 0.018^{\mathrm{B}}$ & $0.421 \pm 0.019^{\mathrm{B}}$ & $0.494 \pm 0.011^{\mathrm{C}}$ & $0.515 \pm 0.010^{\mathrm{C}}$ \\
Group III & $0.239 \pm 0.016$ & $0.382 \pm 0.020^{\mathrm{Cd}}$ & $0.492 \pm 0.008^{\mathrm{C}}$ & $0.579 \pm 0.029^{\mathrm{D}}$ & $0.608 \pm 0.023^{\mathrm{D}}$ \\
Group IV & $0.253 \pm 0.046$ & $0.258 \pm 0.019$ & $0.261 \pm 0.003$ & $0.251 \pm 0.004$ & $0.252 \pm 0.006$ \\
Group V & $0.252 \pm 0.010$ & $0.369 \pm 0.013^{\mathrm{BC}}$ & $0.425 \pm 0.009^{\mathrm{B}}$ & $0.462 \pm 0.004^{\mathrm{B}}$ & $0.468 \pm 0.003^{\mathrm{B}}$ \\
Oral immunity & & & & & \\
Group I & $0.253 \pm 0.015$ & $0.299 \pm 0.004^{\mathrm{B}}$ & $0.358 \pm 0.012^{\mathrm{B}}$ & $0.397 \pm 0.045^{\mathrm{B}}$ & $0.364 \pm 0.026^{\mathrm{B}}$ \\
Group II & $0.244 \pm 0.008$ & $0.333 \pm 0.019^{\mathrm{BC}}$ & $0.410 \pm 0.006^{\mathrm{C}}$ & $0.465 \pm 0.013^{\mathrm{C}}$ & $0.492 \pm 0.017^{\mathrm{C}}$ \\
Group III & $0.250 \pm 0.012$ & $0.365 \pm 0.005^{\mathrm{Cd}}$ & $0.453 \pm 0.023^{\mathrm{D}}$ & $0.526 \pm 0.003^{\mathrm{D}}$ & $0.577 \pm 0.002^{\mathrm{D}}$ \\
Group IV & $0.251 \pm 0.003$ & $0.245 \pm 0.051$ & $0.252 \pm 0.013^{3}$ & $0.259 \pm 0.007$ & $0.249 \pm 0.022$ \\
Group V & $0.257 \pm 0.009$ & $0.268 \pm 0.007^{\mathrm{a}}$ & $0.298 \pm 0.006^{\mathrm{A}}$ & $0.324 \pm 0.004^{\mathrm{A}}$ & $0.277 \pm 0.011^{\mathrm{a}}$ \\
Immersion immunity & & & & & \\
Group I & $0.256 \pm 0.005$ & $0.270 \pm 0.007^{\mathrm{a}}$ & $0.278 \pm 0.008^{\mathrm{a}}$ & $0.281 \pm 0.015^{\mathrm{a}}$ & $0.254 \pm 0.003$ \\
Group II & $0.259 \pm 0.017$ & $0.265 \pm 0.016^{\mathrm{a}}$ & $0.272 \pm 0.004^{\mathrm{a}}$ & $0.271 \pm 0.002^{\mathrm{a}}$ & $0.253 \pm 0.027$ \\
Group III & $0.257 \pm 0.022$ & $0.275 \pm 0.019^{\mathrm{a}}$ & $0.273 \pm 0.011^{\mathrm{a}}$ & $0.278 \pm 0.028^{\mathrm{a}}$ & $0.255 \pm 0.049$ \\
Group IV & $0.252 \pm 0.003$ & $0.255 \pm 0.003$ & $0.253 \pm 0.007$ & $0.25 \pm 0.013^{2}$ & $0.252 \pm 0.005$ \\
Group V & $0.252 \pm 0.009$ & $0.288 \pm 0.003^{\mathrm{a}}$ & $0.300 \pm 0.018^{\mathrm{a}}$ & $0.309 \pm 0.017^{\mathrm{a}}$ & $0.267 \pm 0.007^{\mathrm{a}}$ \\
\hline
\end{tabular}

Different capital letter superscripts in the same column donate extremely significant difference $(P<0.01$; different small letter superscripts donate significant difference $(P<0.05)$

was non-coated $S$. maltophilia inactivated vaccine after ultrasonic disruption immune group. Every group contains 40 l. punctatus (Table 1).

\section{Immunity and blood collection}

Feeding of $I$. punctatus was stopped $12 \mathrm{~h}$ before vaccination and then anaesthetize with $1 \% V / V$ ether. On the first day, different groups of $I$. punctatus was inoculated with PLGA microsphereencapsulated vaccine by the way of injection, immersion and oral immunity; the immune dose is shown in Table 1. On the 14 and 28th days, the same dose was separately taken twice to strengthen immunity. 5 tails were randomly chosen from each group separately on the 1st, 14th, 28th and 42th days to take blood sample on tail vein for standby. The samples were divided into two parts: one was heparinized anticoagulant for the detection of the phagocytic activity of leucocytes and the sterilization activity of phagocyte; the other one was non-anticoagulant for the measurement of serum lysozyme, complement C3, content of protein and antibody IgM.

\section{Measurement of phagocytic activity of leucocytes in blood}

\section{The production of leucocytes suspension}

To begin, $1.0 \mathrm{ml}$ anticoagulant was added to Ficoll-Hypaque (SG = 1.070), centrifuged at $2500 \mathrm{r} / \mathrm{min}$ for $15 \mathrm{~min}$, the leucocytic stratum was picked and suspended with Hank's and counting, then, the cell concentration was adjusted to $1.0 \times 10^{7} \mathrm{cells} / \mathrm{ml}$ (Yu 1983).

\section{Measurement of phagocytic activity of leucocytes in blood leucocytes}

Suspension of $0.5 \mathrm{ml}$ and addition of $0.1 \mathrm{ml} 0.4 \%$ trypan blue was done with equal mixing. The number of living and dead cells were counted by blood cell counting slab in $3 \mathrm{~min}$ and using the leucocytes suspension whose living cell number were no less than $90 \%$ to measure phagocytic activity (Situ and Wu 1996). The samples were divided into 4 parts, then, $0.5 \mathrm{ml}$ Hank's and $100 \mu$ $1.0 \times 10^{8} \mathrm{cfu} / \mathrm{ml}$ Staphylococcus aureus were added with equal mixing. After incubating at $25^{\circ} \mathrm{C}$ for $15,45,75$ and $105 \mathrm{~min}$, the samples were centrifuged at $2000 \mathrm{r} / \mathrm{min}$ (the control group not), giving up supernatant liquor. After washing twice, cells were dissolved with $1.5 \mathrm{ml}, 2 \%$ Tween-20 solution and adding $1 \mathrm{ml}$ MEM, the samples were incubated at $20^{\circ} \mathrm{C}$ for $16 \mathrm{~h}$, with $90 \mu \mathrm{l}$ MTT solution in each tube. After $15 \mathrm{~min}$, we the OD value was measured and the best incubation time selected (Xu, 2005).

\section{The measurement of serum lysozyme}

Under a certain concentration of tubid bacterial liquid, the concentration will decrease and the transmittance will increase because lysozyme can hydrolyze mucopolysaccharide on bacterial cell wall. According to this phenomenon, the content of serum lysozyme can be estimated by the change of turbidity. This experiment adopted the lysozyme test kit (Nanjing Jiancheng the first branch of the Biological Engineering Institute).

\section{The measurement of complement $\mathbf{C} 3$ in serum}

Complement $\mathrm{C} 3$ as antigen in samples can react with $\mathrm{C} 3$ as antibody in reagent, and then form a certain kind of immune complex with some turbidity which has direct proportion with content of complement. Comparing to the standard reagent which was handled through the same way, we can calculate content of C3 in samples. This experiment adopted the complement C3 test kit (Zhejiang Yili Kang Bio-Technology Company Limited). 


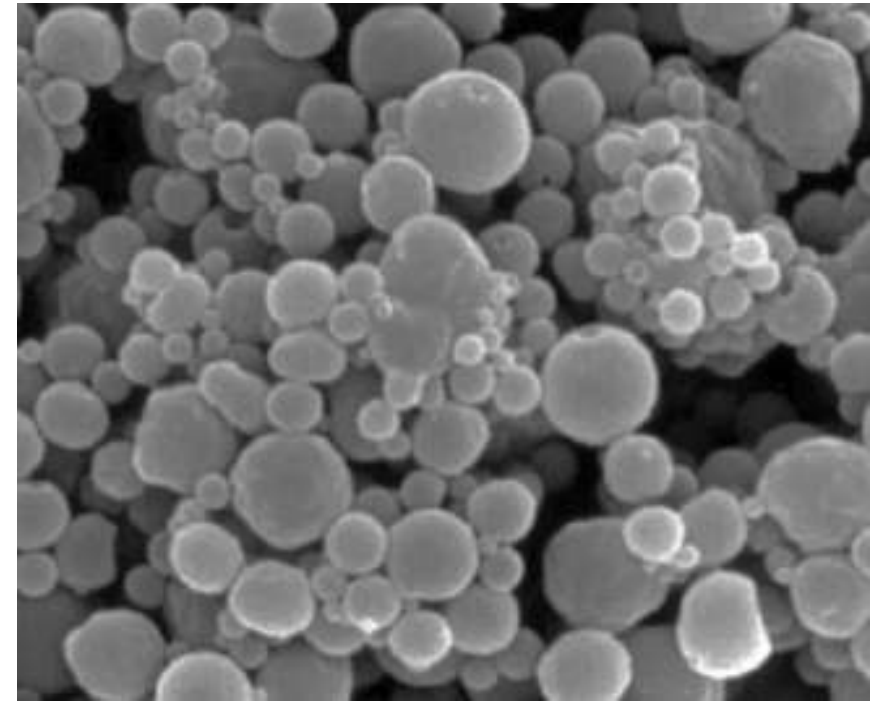

Figure 1. Photograph of scanning electron microscopy of PLGA microsphere-encapsulated vaccine.

\section{The measurement of total amount of serum}

It is known that the protein molecules has $\mathrm{NH}_{3}{ }^{+}$perssad which may join with the negative ion of Coomassile brilliant blue (CBB) dyestuff causing brownish red to turn into blue. According to this theory, the total amount of serum can be calculated by measuring the absorbance. This experiment adopted the CBB-protein test kit (Nanjing Jiancheng the first branch of Biological Engineering Institute).

\section{The measurement of immunoglobulin $M(\lg M)$ in serum}

$\lg \mathrm{M}$ react with the corresponding specific antibody and form immune complex whose turbidity can be measured by transparency method because the turbidity has direct proportion with the content of IgM in serum. This experiment adopted the IgM test kit (Beijing Laibo Bio-Materials Institute).

\section{Toxic attack}

On the 63th day of the experiment, all groups were infected with $S$. maltophilia. To start, I. punctatus light anaesthesia with $1 \%(V / V)$ diethyl ether was given and abdominal cavity injection at a dose of $1 \times 10^{9} \mathrm{cfu} / \mathrm{ml}$ with suspension of $S$. maltophilia, $0.2 \mathrm{ml}$ for single was carried out. Observation and recording of death rate of every groups of $I$. punctatus was done within 30 days. RPS was calculated using the formula below:

$$
R P S(\%)=\frac{D R C-D R E}{D R C} \times 100 \%
$$

Where, DRC, Death rate of control group; DRE: death rate of experiment group.

\section{Statistic analysis}

SPSS17.0 software, LSD and DUCAN, were used to carry out multiple comparisons and to test for significance.

\section{RESULTS}

\section{Measurement of technical index of PLGA microsphere-encapsulated vaccine}

PLGA microsphere suspension prepared by the way of double emulsion evaporation gave a milky white suspension that was easy to lay. The scanning electron micrograph is shown in Figure 1 and the particle size was about $2.2 \mu \mathrm{m}$. Total weight of protein $\left(\mathrm{W}_{\mathrm{T}}\right)$ in suspension with added lipid was $11.20 \mathrm{mg}$ by BCA protein assay kit. Weight of dissociated protein in supernatant liquor was $9.96 \mathrm{mg}$. Encapsulation efficiency of PLGA microsphere was $88.93 \%$.

\section{Measurement of phagocytic activity of leukocytes}

Changes of OD values of phagocytic capacity on leukocytes against Staphylococcus aureus during the experiment are shown in Table 2. Interclass variance results indicated that injection group (groups I to III) of PLGA microsphere-encapsulated vaccine after immunity and non-coated $S$. maltophilia inactivated vaccine injection group (group V) could both extremely significantly $(P<$ 0.01 ) enhance phagocytic activity of leukocytes compared to physiological saline solution control group (group IV). Phagocytic activity of group $\mathrm{V}$ was significantly $(\mathrm{P}<$ 0.01 ) higher than that in group I; Phagocytic activity of leukocytes increased successively and significantly in PLGA microsphere-encapsulated vaccine injection group (group I, II and III). PLGA microsphere-encapsulated vaccine oral group (group I to III) could both extremely significantly $(P<0.01)$ enhance phagocytize capability of leukocytes in each group. The phagocytize capability of non-coated $S$. maltophilia inactivated vaccine oral group (group V) was significantly $(P<0.05)$ higher than that in physiological saline solution control group (group IV) on the 7th day, but was still significantly $(P<0.01)$ lower than that in oral PLGA microsphere-encapsulated vaccine group I. The phagocytize capability of oral groups I to III increased significantly $(\mathrm{P}<0.05)$ with primary immunity and extremely significantly $(P<0.01)$ with intensive immunity, successively. PLGA microsphereencapsulated vaccine immersion group (groups I to III) and non-coated $S$. maltophilia inactivated vaccine immersion group (group V) significantly $(P<0.05)$ enhance phagocytic activity of leukocytes, while there was no significant difference $(P>0.05)$ between these two groups on the phagocytize capability.

\section{Measurement of serum lysozyme level}

Changes in the content of lysozyme in serum are shown in Table 3. Interclass variance results indicated that injection group (groups I- III) of PLGA microsphere- 
Table 2. Changes of lysozyme in serum of Ictalurus punctatus in each group.

\begin{tabular}{|c|c|c|c|c|c|}
\hline \multirow{2}{*}{ Group } & \multicolumn{5}{|c|}{ Lysozyme in serum of Ictalurus punctatus of different days } \\
\hline & 0 & 7 & 21 & 35 & 49 \\
\hline \multicolumn{6}{|c|}{ Injection immunity } \\
\hline Group I & $19.14 \pm 0.25$ & $23.45 \pm 0.32^{A}$ & $26.38 \pm 0.08^{A}$ & $28.51 \pm 0.13^{A}$ & $25.26 \pm 0.39^{A}$ \\
\hline Group II & $19.20 \pm 0.14$ & $25.28 \pm 0.09^{B}$ & $30.46 \pm 0.11^{B}$ & $34.87 \pm 0.53^{C}$ & $36.34 \pm 0.29^{C}$ \\
\hline Group III & $19.29 \pm 0.36$ & $28.37 \pm 0.16^{C}$ & $35.33 \pm 0.25^{C}$ & $41.15 \pm 0.06^{\mathrm{D}}$ & $43.19 \pm 0.33^{D}$ \\
\hline Group IV & $19.25 \pm 0.04$ & $19.36 \pm 0.13$ & $19.23 \pm 0.25$ & $19.32 \pm 0.29$ & $19.48 \pm 0.44$ \\
\hline Group V & $19.31 \pm 0.16$ & $26.91 \pm 0.87^{\mathrm{BC}}$ & $30.87 \pm 0.32^{B}$ & $33.25 \pm 0.15^{\mathrm{B}}$ & $34.19 \pm 1.63^{B}$ \\
\hline \multicolumn{6}{|c|}{ Oral immunity } \\
\hline Group I & $19.72 \pm 0.17$ & $22.36 \pm 0.04^{A}$ & $25.11 \pm 0.33^{\mathrm{B}}$ & $27.62 \pm 0.12^{B}$ & $24.99 \pm 0.04^{A}$ \\
\hline Group II & $19.40 \pm 0.06$ & $25.18 \pm 0.14^{\mathrm{Ab}}$ & $29.74 \pm 0.45^{C}$ & $32.19 \pm 0.35^{C}$ & $33.60 \pm 0.55^{B}$ \\
\hline Group III & $19.71 \pm 0.13$ & $27.02 \pm 0.25^{\mathrm{Bc}}$ & $32.45 \pm 0.02^{\mathrm{D}}$ & $36.22 \pm 0.26^{\mathrm{D}}$ & $38.62 \pm 0.07^{C}$ \\
\hline Group IV & $19.65 \pm 0.30$ & $19.49 \pm 0.06$ & $19.59 \pm 0.07$ & $19.28 \pm 0.18$ & $19.39 \pm 0.03$ \\
\hline Group V & $19.53 \pm 0.23$ & $21.38 \pm 0.53$ & $22.65 \pm 0.07^{A}$ & $23.86 \pm 0.12^{A}$ & $20.66 \pm 0.11$ \\
\hline \multicolumn{6}{|c|}{ Immersion immunity } \\
\hline Group I & $19.24 \pm 0.26$ & $20.62 \pm 0.41^{a}$ & $20.96 \pm 0.66^{a}$ & $20.72 \pm 0.22^{a}$ & $20.17 \pm 0.34$ \\
\hline Group II & $19.08 \pm 0.04$ & $21.19 \pm 0.20^{a}$ & $21.66 \pm 0.14^{a}$ & $21.65 \pm 0.48^{a}$ & $20.75 \pm 0.24$ \\
\hline Group III & $19.11 \pm 0.16$ & $21.25 \pm 0.07^{a}$ & $21.46 \pm 0.25^{a}$ & $21.21 \pm 0.33^{a}$ & $20.77 \pm 0.14$ \\
\hline Group IV & $19.21 \pm 0.19$ & $19.38 \pm 0.21$ & $19.32 \pm 0.12$ & $19.25 \pm 0.13$ & $19.30 \pm 0.08$ \\
\hline Group V & $19.28 \pm 0.03$ & $22.54 \pm 0.29^{A b}$ & $23.89 \pm 0.37^{\mathrm{Ab}}$ & $24.51 \pm 0.90^{\mathrm{Ab}}$ & $21.69 \pm 1.12^{\mathrm{A}}$ \\
\hline
\end{tabular}

Different capital letter superscripts in the same column donate extremely significant difference $(P<0.01)$; different small letter superscripts donate significant difference $(P<0.05)$.

Table 3. Changes of $\mathrm{C}_{3}$ in serum of $I$. punctatus in each group.

\begin{tabular}{lccccc}
\hline \multirow{2}{*}{ Group } & \multicolumn{5}{c}{$\mathbf{C}_{3}$ in serum of Ictalurus punctatus of different days } \\
\cline { 2 - 6 } & $\mathbf{0}$ & $\mathbf{7}$ & $\mathbf{2 1}$ & $\mathbf{3 5}$ & $\mathbf{4 9}$ \\
\hline Injection immunity & & & & \\
\hline Group I & $0.115 \pm 0.008$ & $0.139 \pm 0.006^{\mathrm{A}}$ & $0.153 \pm 0.003^{\mathrm{A}}$ & $0.166 \pm 0.006^{\mathrm{A}}$ & $0.156 \pm 0.007^{\mathrm{A}}$ \\
Group II & $0.118 \pm 0.013$ & $0.148 \pm 0.002^{\mathrm{B}}$ & $0.174 \pm 0.004^{\mathrm{B}}$ & $0.193 \pm 0.004^{\mathrm{B}}$ & $0.202 \pm 0.007^{\mathrm{BC}}$ \\
Group III & $0.122 \pm 0.004$ & $0.161 \pm 0.002^{\mathrm{C}}$ & $0.192 \pm 0.006^{\mathrm{C}}$ & $0.215 \pm 0.005^{\mathrm{C}}$ & $0.234 \pm 0.010^{\mathrm{D}}$ \\
Group IV & $0.113 \pm 0.001$ & $0.120 \pm 0.008$ & $0.122 \pm 0.006^{2}$ & $0.121 \pm 0.004$ & $0.117 \pm 0.005$ \\
Group V & $0.114 \pm 0.019$ & $0.148 \pm 0.009^{\mathrm{BC}}$ & $0.163 \pm 0.001^{\mathrm{B}}$ & $0.174 \pm 0.002^{\mathrm{B}}$ & $0.174 \pm 0.004^{\mathrm{B}}$ \\
Oral immunity & & & & \\
Group I & $0.113 \pm 0.009$ & $0.130 \pm 0.002^{\mathrm{a}}$ & $0.140 \pm 0.002^{\mathrm{Ab}}$ & $0.149 \pm 0.003^{\mathrm{B}}$ & $0.132 \pm 0.007^{\mathrm{B}}$ \\
Group II & $0.115 \pm 0.004$ & $0.139 \pm 0.005^{\mathrm{Ab}}$ & $0.161 \pm 0.003^{\mathrm{C}}$ & $0.180 \pm 0.009^{\mathrm{C}}$ & $0.186 \pm 0.004^{\mathrm{C}}$ \\
Group III & $0.114 \pm 0.009$ & $0.152 \pm 0.004^{\mathrm{BC}}$ & $0.178 \pm 0.003^{\mathrm{D}}$ & $0.202 \pm 0.003^{\mathrm{D}}$ & $0.213 \pm 0.003^{\mathrm{D}}$ \\
Group IV & $0.116 \pm 0.002$ & $0.121 \pm 0.007$ & $0.120 \pm 0.002$ & $0.121 \pm 0.009$ & $0.121 \pm 0.004$ \\
Group V & $0.120 \pm 0.008$ & $0.126 \pm 0.002^{\mathrm{a}}$ & $0.135 \pm 0.003^{\mathrm{A}}$ & $0.138 \pm 0.008^{\mathrm{A}}$ & $0.126 \pm 0.002^{\mathrm{a}}$ \\
Immersion immunity & & & & \\
Group I & $0.114 \pm 0.005$ & $0.122 \pm 0.002^{\mathrm{a}}$ & $0.132 \pm 0.008^{\mathrm{a}}$ & $0.131 \pm 0.009^{\mathrm{a}}$ & $0.120 \pm 0.011$ \\
Group II & $0.115 \pm 0.003$ & $0.125 \pm 0.001^{\mathrm{a}}$ & $0.127 \pm 0.004^{\mathrm{a}}$ & $0.136 \pm 0.008^{\mathrm{a}}$ & $0.122 \pm 0.001$ \\
Group III & $0.117 \pm 0.003$ & $0.127 \pm 0.003^{\mathrm{a}}$ & $0.130 \pm 0.003^{\mathrm{a}}$ & $0.135 \pm 0.004^{\mathrm{a}}$ & $0.122 \pm 0.004$ \\
Group IV & $0.116 \pm 0.006$ & $0.115 \pm 0.008$ & $0.112 \pm 0.018$ & $0.115 \pm 0.003$ & $0.116 \pm 0.010$ \\
Group V & $0.118 \pm 0.004$ & $0.131 \pm 0.005^{\mathrm{A}}$ & $0.140 \pm 0.002^{\mathrm{Ab}}$ & $0.147 \pm 0.004^{\mathrm{Ab}}$ & $0.129 \pm 0.004^{\mathrm{A}}$ \\
\hline
\end{tabular}

Different capital letter superscripts in the same column donate extremely significant difference $(P<0.01)$; different small letter superscripts donate significant difference $(P<0.05$ 
Table 4. Changes of total protein in serum of Ictalurus punctatus in each group.

\begin{tabular}{lccccc}
\hline \multirow{2}{*}{ Groups } & \multicolumn{5}{c}{ Total protein in serum of Ictalurus punctatus of different days } \\
\cline { 2 - 6 } & $\mathbf{0}$ & $\mathbf{7}$ & $\mathbf{2 1}$ & $\mathbf{3 5}$ & $\mathbf{4 9}$ \\
\hline Injection immunity & \multicolumn{5}{c}{} \\
\hline Group I & $39.07 \pm 0.21$ & $44.15 \pm 0.76^{\mathrm{A}}$ & $46.64 \pm 0.37^{\mathrm{A}}$ & $48.22 \pm 0.05^{\mathrm{A}}$ & $46.20 \pm 0.65^{\mathrm{A}}$ \\
Group II & $40.56 \pm 0.29$ & $46.16 \pm 0.18^{\mathrm{B}}$ & $49.88 \pm 0.79^{\mathrm{B}}$ & $52.83 \pm 0.24^{\mathrm{B}}$ & $53.99 \pm 0.29^{\mathrm{B}}$ \\
Group III & $39.82 \pm 0.87$ & $48.32 \pm 0.13^{\mathrm{C}}$ & $53.49 \pm 0.52^{\mathrm{C}}$ & $57.08 \pm 0.28^{\mathrm{C}}$ & $59.46 \pm 0.25^{\mathrm{C}}$ \\
Group IV & $40.37 \pm 2.02$ & $40.38 \pm 2.20$ & $41.18 \pm 1.40$ & $41.47 \pm 0.76$ & $40.36 \pm 1.07$ \\
Group V & $40.46 \pm 1.18$ & $47.50 \pm 0.44^{\mathrm{BC}}$ & $49.58 \pm 0.80^{\mathrm{B}}$ & $51.26 \pm 1.00^{\mathrm{B}}$ & $51.54 \pm 1.04^{\mathrm{B}}$ \\
Oral immunity & & & & \\
Group I & $39.73 \pm 0.88$ & $43.21 \pm 0.33^{\mathrm{A}}$ & $45.98 \pm 0.52^{\mathrm{B}}$ & $47.08 \pm 0.72^{\mathrm{B}}$ & $45.34 \pm 1.19^{\mathrm{A}}$ \\
Group II & $40.00 \pm 1.27$ & $45.58 \pm 0.49^{\mathrm{Ab}}$ & $48.83 \pm 0.60^{\mathrm{C}}$ & $51.63 \pm 0.70^{\mathrm{C}}$ & $53.45 \pm 0.43^{\mathrm{B}}$ \\
Group III & $38.95 \pm 1.60$ & $47.17 \pm 0.45^{\mathrm{BC}}$ & $52.75 \pm 0.69^{\mathrm{D}}$ & $56.11 \pm 0.41^{\mathrm{D}}$ & $58.83 \pm 0.04^{\mathrm{C}}$ \\
Group IV & $40.09 \pm 1.26$ & $40.22 \pm 0.15$ & $40.83 \pm 0.81$ & $41.03 \pm 1.29$ & $39.98 \pm 0.43$ \\
Group V & $40.99 \pm 0.61$ & $42.07 \pm 0.31^{\mathrm{A}}$ & $43.29 \pm 0.46^{\mathrm{A}}$ & $43.85 \pm 0.29^{\mathrm{A}}$ & $41.58 \pm 0.63$ \\
Immersion immunity & & & & \\
Group I & $39.45 \pm 0.72$ & $41.54 \pm 1.28^{\mathrm{a}}$ & $41.36 \pm 1.20^{\mathrm{a}}$ & $41.61 \pm 0.76^{\mathrm{a}}$ & $39.19 \pm 2.70$ \\
Group II & $39.64 \pm 1.63$ & $42.15 \pm 1.75^{\mathrm{a}}$ & $42.60 \pm 1.17^{\mathrm{a}}$ & $41.71 \pm 1.20^{\mathrm{a}}$ & $41.60 \pm 1.74^{\mathrm{a}}$ \\
Group III & $39.95 \pm 1.62$ & $42.34 \pm 0.83^{\mathrm{a}}$ & $42.29 \pm 0.27^{\mathrm{a}}$ & $42.48 \pm 0.08^{\mathrm{a}}$ & $41.02 \pm 2.03$ \\
Group IV & $40.60 \pm 0.17$ & $40.11 \pm 2.41^{\mathrm{B}}$ & $39.97 \pm 1.26$ & $39.74 \pm 2.80$ & $40.19 \pm 1.52$ \\
Group V & $40.12 \pm 0.10$ & $43.57 \pm 0.34^{\mathrm{Ab}}$ & $45.26 \pm 0.58^{\mathrm{B}}$ & $45.97 \pm 0.60^{\mathrm{B}}$ & $43.68 \pm 1.09^{\mathrm{B}}$ \\
\hline
\end{tabular}

Different capital letter superscripts in the same column donate extremely significant difference $(P<0.01)$; different small letter superscripts donate significant difference $(P<0.05)$.

encapsulated vaccine after immunity and non-coated $S$. maltophilia inactivated vaccine injection group (group V) extremely significantly $(P<0.01)$ enhanced the level of lysozyme in serum compared to physiological saline solution control group (group IV). The level of lysozyme in serum of group $V$ was significant $(P<0.01)$ higher than that in group I and was significantly lower after intensive immunity compared to group III; compared to group II, there was no significant difference $(P>0.05)$ on the 7th and the 21th days but was significantly lower on the 35th and the 49th days. PLGA microspheres-encapsulated vaccine oral group (groups I to III) significantly enhanced the level of serum lysozyme of each group. Compared to group IV, serum lysozyme content of group V showed no significant difference on the 7th day and it increased significantly on the 21th and the 35th days but decreased to such an extent close to the control group IV on the 49th day; serum lysozyme content of group $V$ was significant lower than that in group I; PLGA microspheresencapsulated vaccine immersion group (groups I to III) and non-coated $S$. maltophilia inactivated vaccine immersion group (group V) significantly enhance the level of serum lysozyme content; serum lysozyme content of group V was significantly higher than that in group I to III.

\section{Measurement of complement C3 in serum}

Changes of content of complement C3 in serum are shown in Table 4. Interclass variance results indicated that injection group (group I to III ) of PLGA microsphereencapsulated vaccine after immunity and non-coated $S$. maltophilia inactivated vaccine injection group ( group V) significantly $(P<0.01)$ enhance the level of complement C3 in serum compared to physiological saline solution control group (group IV) . Content of serum complement $C 3$ in group $V$ was significantly $(P<0.01)$ higher than that in group I and was significantly lower after intensive immunity compared to group III. Oral group (group I to III) of PLGA microsphere-encapsulated vaccine could significantly enhance the level of complement C3. Compared to group IV, the level of serum complement C3 in group V showed significant difference on the 7th day and then increased significantly on the 21st and the 35th days; decreased on the 49th day but was still above that in group IV. Throughout the whole immune process, the level of complement C3 in group V was significant on the 21 st day and $35^{\text {th }}$ days being lower on the 49th day than that in group I. Immersion group of PLGA microsphereencapsulated vaccine (group I to III) and immersion 
Table 5. Changes of IgM in serum of Ictalurus punctatus in each group.

\begin{tabular}{|c|c|c|c|c|c|}
\hline \multirow{2}{*}{ Groups } & \multicolumn{5}{|c|}{ IgM in serum of Ictalurus punctatus of different days } \\
\hline & 0 & 7 & 21 & 35 & 49 \\
\hline \multicolumn{6}{|c|}{ Injection immunity } \\
\hline Group I & $1.008 \pm 0.015$ & $1.146 \pm 0.014^{\mathrm{A}}$ & $1.298 \pm 0.069^{A}$ & $1.422 \pm 0.015^{\mathrm{A}}$ & $1.334 \pm 0.023^{\mathrm{A}}$ \\
\hline Group II & $0.977 \pm 0.018$ & $1.250 \pm 0.033^{B}$ & $1.531 \pm 0.014^{B}$ & $1.720 \pm 0.040^{B}$ & $1.812 \pm 0.052^{\mathrm{BC}}$ \\
\hline Group III & $0.964 \pm 0.030$ & $1.385 \pm 0.097^{C}$ & $1.724 \pm 0.007^{c}$ & $1.980 \pm 0.058^{C}$ & $2.097 \pm 0.084^{D}$ \\
\hline Group IV & $0.943 \pm 0.034$ & $0.979 \pm 0.021$ & $0.992 \pm 0.027$ & $0.971 \pm 0.015$ & $0.976 \pm 0.035$ \\
\hline Group V & $0.940 \pm 0.033$ & $1.311 \pm 0.022^{B C}$ & $1.481 \pm 0.012^{B}$ & $1.644 \pm 0.018^{B}$ & $1.695 \pm 0.044^{\mathrm{B}}$ \\
\hline \multicolumn{6}{|c|}{ Oral immunity } \\
\hline Group I & $0.962 \pm 0.040$ & $1.122 \pm 0.006^{\mathrm{A}}$ & $1.274 \pm 0.009^{\mathrm{Ab}}$ & $1.410 \pm 0.004^{B}$ & $1.306 \pm 0.017^{A}$ \\
\hline Group II & $0.946 \pm 0.043$ & $1.220 \pm 0.004^{\mathrm{Ab}}$ & $1.458 \pm 0.011^{\mathrm{C}}$ & $1.625 \pm 0.049^{C}$ & $1.753 \pm 0.025^{B}$ \\
\hline Group III & $0.989 \pm 0.042$ & $1.324 \pm 0.046^{\mathrm{Bc}}$ & $1.616 \pm 0.058^{D}$ & $1.837 \pm 0.015^{D}$ & $2.007 \pm 0.023^{C}$ \\
\hline Group IV & $0.988 \pm 0.028$ & $1.003 \pm 0.014$ & $0.981 \pm 0.064$ & $0.981 \pm 0.048$ & $0.929 \pm 0.012$ \\
\hline Group V & $0.958 \pm 0.031$ & $0.987 \pm 0.019$ & $1.145 \pm 0.020^{A}$ & $1.177 \pm 0.005^{\mathrm{A}}$ & $1.017 \pm 0.008$ \\
\hline \multicolumn{6}{|c|}{ Immersion immunity } \\
\hline Group I & $0.966 \pm 0.021$ & $1.046 \pm 0.007^{a}$ & $1.044 \pm 0.020^{a}$ & $1.053 \pm 0.036^{a}$ & $0.995 \pm 0.040$ \\
\hline Group II & $0.955 \pm 0.030$ & $1.029 \pm 0.019^{a}$ & $1.088 \pm 0.027^{a}$ & $1.087 \pm 0.010^{a}$ & $1.023 \pm 0.025$ \\
\hline Group III & $0.960 \pm 0.028$ & $1.054 \pm 0.042^{a}$ & $1.073 \pm 0.014^{a}$ & $1.060 \pm 0.072^{a}$ & $1.003 \pm 0.026$ \\
\hline Group IV & $0.950 \pm 0.060$ & $0.963 \pm 0.070$ & $0.969 \pm 0.020$ & $0.952 \pm 0.033$ & $0.949 \pm 0.005$ \\
\hline Group V & $0.922 \pm 0.038$ & $1.102 \pm 0.007^{\mathrm{Ab}}$ & $1.181 \pm 0.042^{B}$ & $1.220 \pm 0.056^{\mathrm{B}}$ & $1.010 \pm 0.023^{A}$ \\
\hline
\end{tabular}

Different capital letters superscripts in the same column donate extremely significant difference $(P<0.01)$ different small letter superscripts donate significant difference $(P<0.05)$.

group of non-coated S. maltophilia inactivated vaccine (V group) significantly enhanced the level of serum complement C3. The content of serum complement C3 in group $V$ was significantly higher than that in group I to III on the 21 st and 35th day.

\section{Measurement of total protein}

Changes in the total protein are shown in Table 5. Interclass variance results indicated that injection group (group I to III) of PLGA microsphere-encapsulated vaccine after immunity and non-coated $S$. maltophilia inactivated vaccine injection group (group V) significantly $(P<0.01)$ enhanced the content of total protein compared to physiological saline solution control group (group IV). The level of total protein in group $\mathrm{V}$ was significant higher than that in group I but lower than that in group III after intensive immunity with no significant difference $(P>0.05)$ compared to group II. Oral group (groups I to III) of PLGA microsphere-encapsulated vaccine significantly enhanced the level of total protein. Level of total protein in group $\mathrm{V}$ was significantly higher than that in group IV on the 7th, 21st and the 35th days and to the same extent lower than that in groupl after intensive immunity. Immersion group of PLGA microsphereencapsulated vaccine (group I to III), except that in the 49th week, showed no significant difference and immersion group of non-coated $S$. maltophilia inactivated vaccine (group V) could extremely significantly enhance the level of total protein. The level of total protein in group $V$ on the 7th day was significant and on the 21th, the 35th and the 49th days were extremely significant higher than that in group I to III.

\section{Measurement of antibody, IgM}

Changes in the level of antibody, IgM, were are shown in Table 6. Interclass variance results indicated that injecttion group (groupl to III) of PLGA microsphere-encapsulated vaccine after immunity and non-coated $S$. maltophilia inactivated vaccine injection group (group V) significantly $(P<0.01)$ enhanced the level of IgM compared to physiological saline solution control group (group IV). The level of IgM in group $\mathrm{V}$ was significantly higher than that in group I but lower than that in group III after intensive immunity. Oral group (group I to III) of PLGA microsphere-encapsulated vaccine significantly enhanced the level of IgM in all groups. Content of IgM in non-coated $S$. maltophilia inactivated vaccine oral group (group V) on the 7th day showed no significant difference and on the 21th and the35th days increased significantly compared to control group (group IV). Immersion group of PLGA microsphere-encapsulated vaccine (group I to III) and immersion group of non-coated $S$. maltophilia inactivated vaccine (group) significantly enhanced the level of IgM. The level of IgM in group $V$ was significant 
Table 6. Protective effects of PLGA microparticles on Ictalunes punctatus against $S$. maltophilia.

\begin{tabular}{lccc}
\hline Groups & Dosage & Survival no./Total no. & RPS \\
\hline \multicolumn{1}{l}{ Injection immunity } & & \\
\hline Group I & $50 \mu \mathrm{g} /$ tail & $19.67 / 40$ & $49.17 \%$ \\
Group II & $100 \mu \mathrm{g} /$ tail & $26.67 / 40$ & $66.68 \%$ \\
Group III & $200 \mu \mathrm{g} /$ tail & $29.33 / 40$ & $73.33 \%$ \\
Group IV & $0.2 \mathrm{ml} /$ tail & $0 / 40$ & 0 \\
Group V & $200 \mu \mathrm{g} /$ tail & $25.66 / 40$ & $64.17 \%$ \\
Oral immunity & & \\
Group I & $50 \mu \mathrm{g} /$ tail & $17.33 / 40$ & $43.33 \%$ \\
Group II & $100 \mu \mathrm{g} /$ tail & $26 / 40$ & $65 \%$ \\
Group III & $200 \mu \mathrm{g} /$ tail & $30 / 40$ & $75 \%$ \\
Group IV & $1 \mathrm{ml} /$ tail & $0 / 40$ & 0 \\
Group V & $200 \mu \mathrm{g} /$ tail & $2.67 / 40$ & $6.68 \%$ \\
Immersion immunity & & \\
Group I & $50 \mu \mathrm{g} / \mathrm{ml}$ & $0.33 / 40$ & $0.83 \%$ \\
Group II & $100 \mu \mathrm{gg} / \mathrm{ml}$ & $0 / 40$ & 0 \\
Group III & $200 \mu \mathrm{g} / \mathrm{ml}$ & $1 / 40$ & $2.5 \%$ \\
Group IV & $0.7 \%$ & $0 / 40$ & 0 \\
Group V & $200 \mu \mathrm{g} / \mathrm{ml}$ & $4.66 / 40$ & $11.66 \%$ \\
\hline \multicolumn{6}{c}{}
\end{tabular}

after primary immunity and extremely significant after intensive immunity higher than that in group I to III.

\section{The protective effect of PLGA microsphere- encapsulated vaccine}

After immunizing all groups of $I$. punctatus for 3 times, toxic attack with living $S$. maltophilia suspension were performed by the way of abdominal cavity injection on the 63th day. 14 days later, the statistics of mortality in each group and the relative survival rate were calculated. Relative survival rate in injection groupl to III was higher by $9.16 \%$ compared to group V; Groupl to III of different dose with the same route of oral immunity both significantly $(P<0.01)$ enhanced the protective effect on $I$. punctatus compared to group $\mathrm{V}$, indicating that PLGA microsphere-encapsulated vaccine could protect antigen from gastrointestinal damage and promote the immune protective effect on I. punctatus effectively. Groups I to III of different dose with the same route of immersion immunity showed no significant difference $(P>0.05)$ on the protective effect compared to group IV while they were significantly lower than that in group V. After exposing group IV to toxic attack, dead fish showed typical symptoms of surface congestion, body-color fades, abdominal swelling, ascites and intussusception. Some $I$. punctatus got infected and became sick in each immune groups due to the immunity protective failure occurring at different extent, but the extent of falling ill in immune groups was less than that in non-immune groups.

\section{DISCUSSION}

\section{Effect of S. maltophilia vaccine on leucocytes phagocytic activity of $I$. punctatus}

Fishes are lower vertebrates and their specific immunity mechanism is not perfect, so non-specific immunity is paramount to them (Qian et al., 2003). Leucocytes such as granulocyte, monocyte and lymphocyte that also belong to phagocyte of osteichthyes and their composition of mononuclear phagocyte system are the important defense system and with that, fish can capture antigen and remove pathogenic microorganism (Liu et al., 1999). Phagocyte of animals can engulf eye winker in body and keep information of antigen and pass it to the relevant lymphocyte at the same time for digesting the pathogenic microorganism and subsequently stimulating humoral and cellular immunity. Therefore, measurement of phagocytic activity of leucocytes of fish can be used to judge the immune status of tested fish. This experiment detected the phagocytic activity of leucocytes of two groups (test and control groups) of $I$. punctatus. The test group was inoculated with vaccine such as $S$. maltophilia PLGA microsphere-encapsulated vaccine, non-coated $S$. maltophilia inactivated vaccine after ultrasonic disruption and liposome vaccine via the following immune routes: injection, immersion and oral method. It turned out that inoculating farmed fish againt $S$. maltophilia could effectively increase their phagocytic activity of leucocytes. We also found that $l$. punctatus acquired a significant humoral immune response in our later determination of immune index. Clem et al. (1995) reported that we could isolate phagocyte from blood or varieties of immune organs and with inactivated $S$. aureus bacteria body coincubation period of time, then smeared and observe the situation of phagocyte against bacteria body to determine phagocytic activity of fish. Method for detecting phagocytic activity of fish needs a heavy workload to observe and count the phagocyte although it has advantages like user-friendly control, less demanding on experimental conditions, etc. This experiment adopted methylthiazoletetrazolium (MTT) staining technique which is user-friendly control and repeatable to detect phagocytic function of leukocytes and it has been proven to be a better test method of phagocytic function of fish (Xu, 2005).

\section{Effect of S. maltophilia vaccine on serum lysozyme activity}

Lysozyme is hydrolase specialized in cell wall of microbe and is an important part of non-specific immune system of fish (Samuel et al., 1996). Lysozyme mainly wreck 
glycan chain between $\mathrm{N}$-acetylmuramic acid and $\mathrm{N}$-acetyl glucosamine of cell wall in Gram-positive bacteria, so that cell wall lose toughness and bacteria schizolysis occur and subsequently bacteria are destroyed. As gramnegative bacteria, lysozyme mainly play a role right after the complement and other enzymes have destroyed the outer bacterial cell wall and the exposure of inner cells peptidoglycan (Yang and Zuo, 1993, ChenTerutoyo and Alexandra, 1996). In addition to direct sterilization, lysozyme can enhance bacteriolysis which is complementmediated. Meanwhile, it also has damaging effects on fungi, parasites and viruses (Wang et al., 2000). Therefore, lysozyme is of great important for fish to resist various kinds of pathogen, especially in the high-density culture environment, and plays a crucial role in enhancing resistance to disease in fish. Activity of lysozyme in serum of fish can rise due to the contact between body and antigenic substances or the immunologic stimulant. Siwiki et al. (1987) used Pseudomonasalcaligenes and Actinodiscus punctata to infect carp and measurement showed that the activity of lysozyme markedly improved (Siwicki and Studnicka, 1987). It has been found that lysozyme exists universally in serum of fish and is the material foundation of phagocyte to decide whether the phagocyte kills pathogenic bacteria and subsequently undermine and eliminate variety of pathogenic microorganisms that invade the body to achieve body's defense function. Therefore, measurement of lysozyme activity of fish can to some extent reflect the immune status of non-specific humoral immune response of fish (Jorgensen et al., 1993). In this experiment, we confirmed that vaccinating farmed fish could effectively improve the level of serum lysozyme.

\section{The effect of $S$. maltophilia vaccine on content of serum complement}

Complements are a group of globulin existing in animal organism, which are related to immunity and with enzymatic activity and self-regulation and are mainly synthesized from liver cells and macrophagocytes. Complement in serum mainly come from liver cells and in the area with inflammation, from macrophagocytes. Currently, it has been found that aquatic vertebrates like Anguilla japonica, carp, ayu, I. punctatus and Tilapia mossambica among others possess complement activation route which is similar to that in mammal. The route is divided into classical and bypass activation (Cao, 2006). Complements have no specificity and their activities are unsteady. But they have effects on bacteriolyzing, inactivating virus, dissolving cells, immune adhesion, regulating phagocyte and chemotoxis, which play an important role in maintaining the body's own stability and anti-infections immunity (Gong, 1999). Among components of complement, content of $\mathrm{C} 3$ is the highest. $\mathrm{C} 3$ is the hinge between the classical and the bypass activation route of complement and also is the medium to connect antibody with phagocytes. It can enhance the specific immunity mediated by humors and cells and is the key component of the compliment system in fish (Manning et al., 1994; Sakai, 1992). So C3 is very important to fish. The result of this experiment showed that vaccinating $S$. maltophilia vaccine on farmed fish could effectively promote complement C3.

\section{The effect of S. maltophilia vaccine on content of serum protein}

Changes of composition and content of serum protein in fish have a close relationship with fish's health, nutrition and disease conditions, which can reflect the pathological status of body and immune function. When fish are hungry or sick, the protein content decreased significantly. The elevated levels of serum protein may be affected by activation of the body's metabolism and the synthesis system. According to the report, oyster infected by Perkinsus marinus and clam infected by $P$. atlanticus both showed consistency of increased serum protein. This phenomenon may due to the fact that the body was irritated resulting from the humoral response and subsequently, synthesized the specific polypeptides. Liu et al. (1999) reported that elevated level of serum protein could make the level of humoral factors like lysozyme substances and sterilization substances in serum increased, thereby enhancing the body's own disease resistance ability (Liu et al., 1999). The result of this experiment confirmed that vaccinating $S$. maltophilia vaccine on farmed fish could effectively increase the content of humoral factors like lysozyme substances and sterilization substances in serum of $l$. punctatus and then increased the content of serum protein and subsequently enhanced resistance to disease in fish.

\section{Effect of S. maltophilia vaccine on content of IgM}

Fishes are one of the animals which produced immune globulin earliest. From the perspective of system evolution, the lower the status animals, the fewer types of immune globulin they produce. The studies have shown that the main types of immune globulin in fish are similar to the $\lg \mathrm{M}$ in mammal in these following aspects: secondary structure, electrophoretic mobility, molecular weight, heavy $(\mathrm{H})$ and (light) $\mathrm{L}$ chain of molecular weight and the molecular weight of $\mathrm{H}, \mathrm{L}$ chain and function; and their share of the relative level of serum total protein amount is higher than that in mammal (Kobayashi and Tomonaga, 2000). This study found that changes in trends of globulin are consistent with immune globulin. The results showed that the level of serum IgM was the highest at $200 \mu \mathrm{g} /$ tail in group PLGA microsphere-encapsulated vaccine with injection immune route. Content of 
serum IgM in group PLGA microsphere-encapsulated vaccine with oral immune route was higher than that in the group non-coated $S$. maltophilia inactivated vaccine, indicating PLGA organism biodegradable polyester to protect antigen from gastrointestinal enzymes and the acidic environment (Mestecky et al., 1994). Li et al., (2006) did tracer research on PLGA practically wrapped with model protein and it showed that fish disease vaccine with PLGA as its carrier could effectively be absorbed through the intestinal tract. It has been found that in this experiment, the level of serum IgM showed significant difference $(P<0.01)$ when PLGA microsphereencapsulated vaccine' dose at $100 \mu \mathrm{g} /$ tail and $200 \mu \mathrm{g} /$ tail was administere. The level of serum $\operatorname{lgM}$ in group PLGA microsphere-encapsulated vaccine with immersion immune route was lower than that in the group noncoated $S$. maltophilia inactivated vaccine with immersion immune route. We found that PLGA partially settled down soon after being suspended in water which may be the reason for poor immune effects. Rombout, (1993) found that oral vaccine could increase the level of immune globulin (Ig) in intestinal mucus and four times higher than that in serum. Injection vaccine could make content of $\mathrm{lg}$ in serum higher than that in mucus. Immersion method could significantly increase the mucus in skin (Rombout, 1993).

Immersion immunity in this study had bad effect compared to the use of injection and oral, which might be because the fish has its own mucosal immune system. Lobb, (1987)'s research is in line with the above. He used soluble antigen like dinitrophenyl-oriented horse serum albumin to give immune immersion to $I$. punctatus and then found that it could produce specific mucus antibody response, while IgM in serum could not easily be transferred to the skin mucus through the vessel, which suggested that IgM in fish's mucus might be produced locally rather than transferred from the serum (Lobb, 1987). More and more researches have shown that there may exist local mucus secretion system in fish (Rombabout and den Van, 1989).

\section{Toxic attack}

After being exposed to toxic attack with $S$. maltophilia, the control group showed typical symptoms like ascites and intussusception, as same as those natural cases with morbidity and mortality rates by $100 \%$. While I. punctatus in the injection group got sick and died after immunizing with PLGA microsphere-encapsulated vaccine, they specifically manifested the incidence decreased with the immune dose increasing. In a word, morbidity in PLGA microsphere-encapsulated vaccine immune group was lower than that in non-coated $S$. maltophilia inactivated vaccine group and in physiological saline solution control group and its symptoms were not typical. After carrying out toxic attack, relative immune protection rates in PLGA microsphere-encapsulated vaccine immune group were both significantly $(\mathrm{P}<0.01)$ higher than that in non-coated $S$. maltophilia inactivated vaccine group, which indicated PLGA microsphere-encapsulated vaccine could protect antigen from the gastrointestinal damage and promote the immune protective effect on $I$. punctatus effectively. Immersion route with different dose of PLGA microsphere-encapsulated vaccine group in the protection effect, showed no significant difference $(P>$ 0.05), compared to physiological saline solution control group, which might be due to PLGA microsphereencapsulated vaccine particle with huge quality being easy to precipitate without being absorbed effectively.

\section{ACKNOWLEDGEMENTS}

This work was supported by Program for Changjiang Scholars and Innovative Research Team in University (No.IRT0848), Science and Technology project of Sichuan Province (No.08ZA082).

\section{Abbreviations}

PLGA, Poly(D,L-lactide-co-glycolide); TSB, tryptone soy broth; CBB, Coomassile brilliant blue; IgM, immunoglobulin M; MTT, methylthiazoletetrazolium.

\section{REFERENCES}

Ben GB (2002). Specific detection of $S$. maltophilia strains in albacore tuna (Thunnus alalunga) by reverse dot-blot hybridization. Food Control, 13: 293-299.

Cao HM (2006). Research on the effect of 2 united vaccine and drugs on immunity of Turbot. In. China Ocean University, Qingdao.

Chen SC, Terutoyo Y, Alexandra A (1996). Immune response of Rainbow Trout to extracellular Products of mycobacterium spp. J. Aquat. Anim. Health, 8: 216-222.

Durborow RM, Hanson L (1988). Severed intestine in Channel catfish. J. Wildlife Dis. 24: 146-149.

Geng Y, Wang KY (2005). A preliminary report of an acute epidemic and infectious disease in Channel catfish. Scientific Fish Farming, 16: p. 51.

Geng Y, Wang KY, Chen DF (2006). Separation,identification and phylogenetic analysis of an infectious pathogen in Channel catfish. J. Microbiol. 46: 28-31.

Gong XW (1999). Comparative study of Soft-shelled turtle lake groups and the Taiwan groups'resistance to disease. Research on the improvement effect of Yulei bacteria and the PSB on the greenhouse turtle pond water quality. In Shanghai Fisheries University, Shanghai.

Harris NB (2001). Septicemia associated with $S$. maltophilia in a West African dwarf crocodile (Osteolaemus tetraspis subsp. tetraspis). J. Vet. Diagnostic Investigation, 13: 255-258.

Huang B, Chen SF (2002). Study of cystic disease in Yellow-margined box turtle. Freshwater Fish. pp. 44-46.

Hugh R (1961). Pseudomonas maltophilia, an alcaligenes-like species. J. Gen. Microbiol. 26: 123-132.

Jeffery DS, O'hagan D (1993). The preparation and characterisation of poly (lactide-co-glycoude) microparticles. The Entrapment of a model protein using a (water-in-oil) -in-water emulsion solvent evaporation technique. Pharm. Res. 10: 362-368.

Johnson EH (2003). An outbreak of lymphadenitis associated with Stenotrophomonas (Xanthomonas) maltophilia in Omani goats. J. Vet. Med. Series B 50. 
Jorgensen JB, Sharp GJE, Secombes CJ (1993).Effect of a yeast-cellwall-glucan on the bactericidal activity of rainbow trout macrophages. Fish Shellfish Immunol. 3: 267-277.

Kim S, Doh H, Ahn J (1999). Induction of mucosal and systerm immune response by oral immunization with $H$. Pylori lysates encapsulated in poly(DL-lactide-co-glycoilde) microparticles. Vaccine, pp. 607-616.

Kobayashi K, Tomonaga S (2000). The second immunoglobulin variable-region diversity in the zebrafish. Immunogenetics, 52: 81-91.

Li GN, Jiang DF (2004). The encoding identification of 28 strains pathogenic in aquatic animals. Water Conservancy Fish. pp. 62-64.

Li L, Liu ZG, Yu HQ (2006). Study and tracing study of a new oral vaccine against fish diseases. J. Trop. Med. 6:382-384.

Liu SQ, Jiang XL, Mou HJ (1999). Effect of polysaccharide on Japanese shrimp immune serum enzyme activities. China Fish. Sci. 6: 107-108.

Liu Y, Chen CF, Zhang YZ (1999). The immune research on bacterial fish disease. Jiang Xi Science, 17: 121-130.

Lobb CJ (1987). Secretory immunity induced in catfish, Icialurus punctatus, following bath immunization. Dev. Comparative Immunol. 11: 727-738.

Manning MJ, Fishes A, Tumer RJ (1994). Immonology: A Comparative Approach, Britain John Wiley Sons Ltd.

Mestecky J, Moldovesnu Z, Novak M (1994). Biodegradable microspheres for the delivery of oral vaccines. J. Controlled Release, 28: 131-141.

Qian YX, Wang GL, Shao JZ (2003). The non-specific immune regulation of fishes. Ningbo University Learned J. (Polytechnic Edition) 13: 95-99.

Rombout JH (1993). Difference in mucus and serum immunoglobulin of carp. Dev. Comparative Immunol. 17: 309-317.

Sakai DK (1992). Repertoire of complement in immunological defense mechanisms of fish. Annu. Rev. Fish Dis. pp. 223-247.

Samuel M, Lam TJ, Sin YM (1996). Effect of laminaran[ $\beta(1,3)$-D-glucan] on the protective immunity of blue gourami, Trichogaster trichopterus against Aeromonass almonicida. Fish Shellfish Immunol. 6: 443-454.

Situ ZQ, Wu JZ (1996). Cell Culture, World Book Publishing Company, Xi'an.

Siwicki A, Studnicka M (1987). The phagocytic abi1ity of neutrophils and serum 1ysozyme Activity in experimental1y infected carp, Cyprinus carpio L. The phagocytic abi1ity of neutrophils and serum 1ysozyme Activity in experimental1y infected carp, Cyprinus carpio L, 31(Supplement A), pp. 57-60.

Wang HT, Xu YL, Zhang PJ (2000). Research on lysozyme specific activity in Fake male flounder's different tissues. Marine Sci. 24: 7-8.
Wang KY, Geng Y, Huang XL (2006a). Infectious disease of intussusception in Channel catfish and its prevention. Freshwater Fish. 36: 61-64.

Wang KY, Geng Y, Huang XL (2006b). Infectious disease of intussusception in Channel catfish. Modern Fish. Information, 21: 3-8.

$\mathrm{Xu} X(2005)$. The effect of a-mannan-peptides on immune factors in crucian carp. Northwest Agriculture and Forestry University.

Yang XL, Zuo WG (1993). Cell culture from Grass Carp's hemorrhage disease and its inactivated vaccine research: effect of vaccine stability, adjuvant reagent and strengthening immunity on immune response of Grass Carp. Aquat. Biol. 17: 46-52.

Yu H (1983). Medical Microbiology, Beijing: People's Health Press, Beijing.

Zhang HJ, Xie MQ (2004). Clone and sequence analysis of 16srRNA gene in swine narrow S. maltophilia. Chinese Vet. Sci. Technol. pp. 3-5.

Zhou YC, Zhu WH (2001). Pathogen causing massive death of Trachinotus ovatus and its control. Marine Sci. pp. 40-44. 